\title{
Research on Construction of Teaching Resource Library Base of IC Manufacturing Process
}

\author{
Shu-ping LI \\ Suzhou Industrial Park Institute of Services Outsourcing, Suzhou, Jiangsu, China
}

Keywords: Teaching Resource Library; Nanofabrication Technology; Information Technology.

\begin{abstract}
In recent years, it has become an important content of education informatization to promote the common construction, sharing and application of quality resources. Taking IC Manufacturing Process course as an example, this paper explores and studies the significance, basic ideas, construction content, construction method and practice innovation of open, shared, intelligent and dynamic teaching resource library. The construction of this teaching resource library provides students with independent learning and practice platform, and provides an important support for the training of highly skilled applicators of nanofabrication technology.
\end{abstract}

\section{Introduction}

Education informatization is one of the most profound changes in the history of education development. The construction and development of educational resources is the foundation of education informatization. It is the important content of education informatization to promote the common construction, sharing and application of quality resources. The application of educational information technology in the field of higher vocational colleges and universities is aimed at promoting teaching reform, raising the level of professional construction, and training innovative talents in technical skills that meet the needs of enterprises.

This paper explores and studies the significance, basic ideas, construction content, construction method and practice innovation of open, shared, intelligent and dynamic teaching resource library.

\section{The Significance and Ideas of the Construction of Teaching Resource Library of IC Manufacturing Process}

\subsection{The Significance of Teaching Resource Library of IC Manufacturing Process}

At present, the new growth point of nano-industry in Suzhou is gradually shifting to the higher value-added nano-device and system. Therefore, as an important part of nanotechnology industry, nanofabrication technology is also in rapid development. The vigorous development of the industry has led to the strong demand for nanofabrication technology talents. The core course of microelectronics technology major - "IC Manufacturing Process" is set up for the development of nanofabrication technology technicians needed for the development of semiconductor enterprises. The development of teaching resource library of "IC Manufacturing Process" is mainly aimed at students of microelectronics major in higher vocational colleges, related engineering and technical personnel and microelectronics enthusiasts. It is of great practical significance to provide a very systematic, professional and comprehensive "IC Manufacturing Process" learning platform for the vast number of learners.

\subsection{Construction goals and Ideas of Teaching Resource Library of IC Manufacturing Process}

The goal of resource construction is to build an open sharing teaching resource library of "IC Manufacturing Process" through the system design, advanced technology support, network operation, open management, dynamic and continuous update mode, which can reflect the latest achievements and characteristics of the reform of modern vocational education, and which can meet the needs of the teaching of microelectronic technology in higher vocational education and the training needs of the enterprise nanofabrication technology technicians. Through the study of the 
resource library, learners can master semiconductor devices with integrated circuit as the representative of the manufacturing process, the semiconductor device manufacturing process principle and operating method of the process, analysis method of process parameter detection and process quality, so that students have the ability of process equipment operation, process detection, process analysis, and have a certain process design and process management capability.

Establish a teaching resource library to ensure the effectiveness of teaching resources based on the professional ability requirements of relevant technical positions in enterprises. The "IC manufacturing process" course is the core course of microelectronics technology. It is mainly used to train micro and Nano-processing technicians. This course is based on the company's research, adopting "research and analysis of enterprise needs, to make clear professional training objectives and job positioning, and the typical tasks of the job $\rightarrow$ Inducing action areas $\rightarrow$ Transforming the learning domain curriculum are scientifically constructed, and the construction of the teaching resource library of the course is based on the results of the previous course construction and has been achieved through the development and construction. All teaching resources developed are closely linked to the needs of employment, ensuring the effectiveness and pertinence of teaching resources.

Diversified course teaching resources development to fully meet the needs of all audiences and realize common development and sharing. The construction of the curriculum resource library closely follows the latest Nano-processing technology development achievements and technology and the principle of work-study combination, scientification and dynamics. It was jointly constructed with the cooperative enterprises represented by other institutions and the Nano processing platform of the Chinese Academy of Sciences. At the same time, the system has established smooth and diverse resource collection channels to ensure that the content of resources is closely integrated with the industry's latest technology, production practices, and related professional standards. Also the content is scientifically accurate, diverse, and adaptable to different learning objectives (including students and corporate employees, etc.). On the other hand, the constructed resource library is convenient for operation and use, fully reflecting its features of ease of use, practicality, scientificity, sharing, and extensibility.

Focus on the feasibility of teaching implementation and guide the reform of teaching model. By exploring the online teaching mode of the course, we can fully optimize online education resources, enrich and improve the teaching mode and teaching methods of the course teaching under the network environment, improve the teaching effect, and practice and popularize the results of resource library construction in teaching and training.

Construct a Virtual Environment for Curriculum Training to Enable Students to Study Independently. A more advanced process virtual environment for IC manufacturing processes is an effective and necessary supplement for on-the-spot training, which facilitates the development of independent online learning by learners.

\section{Content of Teaching Resource Library}

The construction of the teaching resource library needs to take into account the characteristics of the discipline, the actual environment of the on-the-spot teaching, the existing training conditions, and the learning ability and needs of different types of learners. Therefore, the construction of the "IC Manufacturing Process" course teaching resource library is not a simple process of stacking teaching materials such as pictures, animations, videos, and other teaching materials, but a complex system. The framework of the course teaching resource library needs to promote students' independent learning and inquiry learning. The teaching resource provided need to give learners various aspects of information stimulation to stimulate their interest in learning. The homepage of this course teaching resource library is shown in Figure 1.

\subsection{Course Research and Revision of Course Standards}

Through multiple corporate surveys and integration of the company's latest job knowledge and ability needs, the microelectronics technology professional training program was revised to further 
clarify professional training objectives. On the basis of further clarifying the knowledge and skills requirements of the micro- and Nano-processing technician positions, we should reorient the training objectives of the "IC manufacturing process" course to clarify the position of the course in the professional training and the logical relationship with the previous and subsequent courses of knowledge, we should revised the course standards again, and shifted the focus of theoretical teaching to training students' practical ability. In terms of course content selection and skill training, in view of the characteristics of vocational education, the practical and technical requirements are highlighted around the requirements of the post knowledge and skills of the integrated circuit manufacturing enterprises. It is mainly reflected in the following points: the course content meets the requirements of the company's micro-Nano processing technicians' job tasks; the implementation of the project takes the process flow of the IC manufacturing process as a step, from simple to complex; the content organization is based on the modular teaching of the IC manufacturing process flow The teaching content includes the basic module, the core module, the expansion module, and the promotion module; the practical training mode combined with the virtual training and the off-campus training; the implementation of the teaching project is based on the standards of the semiconductor chip manufacturing industry and linked with professional qualification certificate.

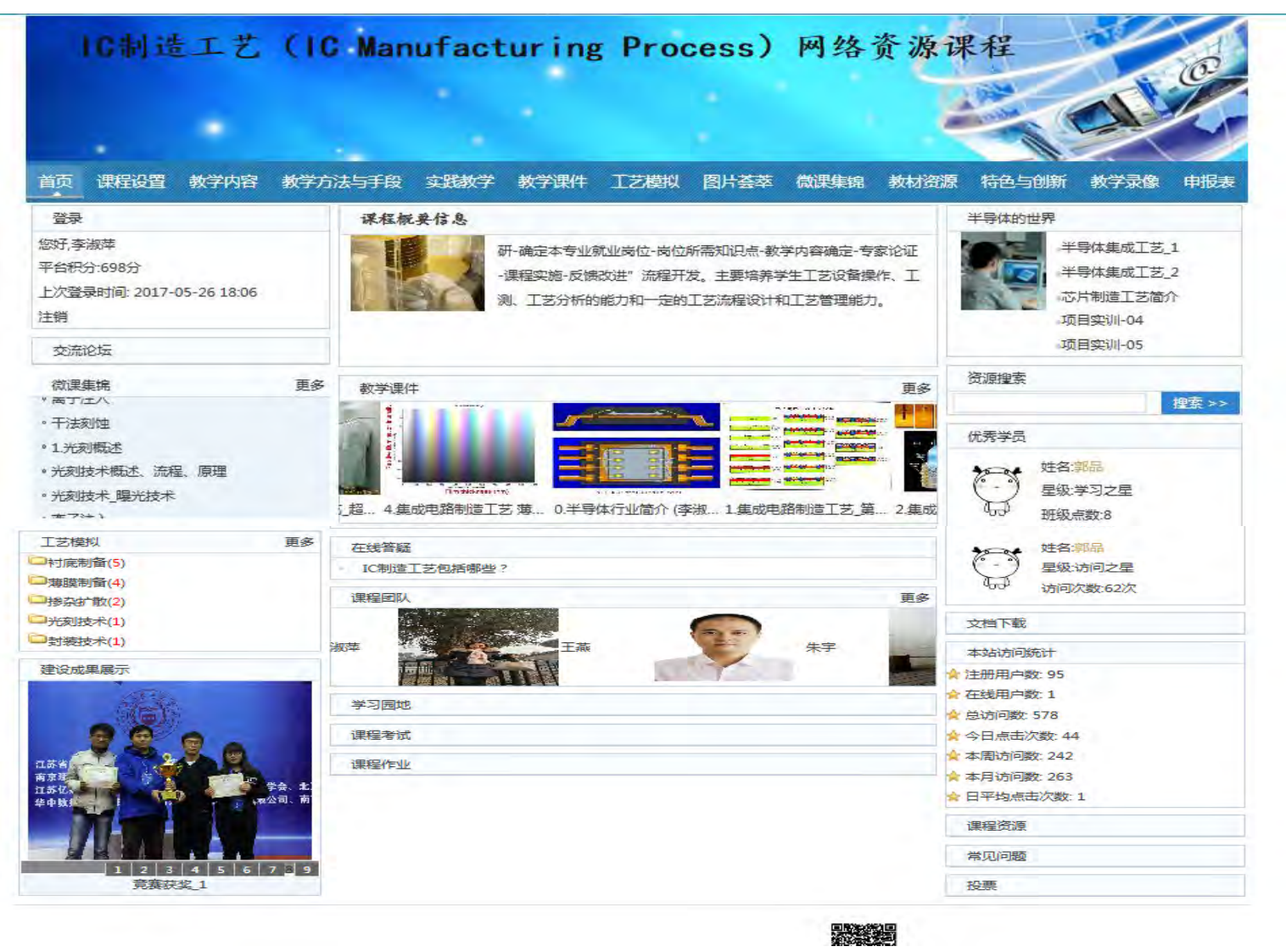

Figure 1. Teaching Resources Library Home

\subsection{Deepen the Course Teaching Content System and Process Fragmented Course Content}

Combined with the revised curriculum standards, the course content analysis, knowledge deconstruction, determination, and refinement of the knowledge points contained in the teaching unit and the various teaching units, according to the logical relationship between knowledge points, build a knowledge network map of the course. The teaching content is integrated into four modules. The first module is the basic module: the understanding of the silicon planar process, which is the development of the integrated circuit manufacturing process and the introduction of the general process flow, enabling students to have an overall understanding of the manufacturing process of semiconductor devices and circuits and laying the foundation for learning a single process. The 
second module is a core module and is divided into two parts: the front process and the back process. The front process introduces the core process of IC manufacturing (film preparation, photolithography, etching, doping, CVD, metallization, etc.). It is the focus of this course, and the five parts correspond to the division of labor of the five major categories of companies. It is more targeted to adapt students to work positions as soon as possible after entering the company. The latter procedure mainly introduces the packaging and testing technology of the integrated circuit, enabling the learner to understand the operation of the process, and provide support for the technician positions. The third module is an extension module: it mainly includes substrate preparation, clean room, and clean technology, enabling students to understand the materials, supporting resources, and environmental requirements required for the core process. The fourth module is the promotion module, which provides comprehensive training in the knowledge of the course and enhances students' professional skills, laying the foundation for the students' subsequent development.

\subsection{Course Teaching Courseware, Video Material Production and Improvement}

The material teaching resource is the provider of the course teaching resources. According to the media type, it can be divided into text, picture, audio, video, and animation. Among them, the picture material mainly comes from the teaching reflects the teaching team, the student's work, the typical links and teaching scenes in the teaching content. The production of teaching courseware PPT is based on the knowledge structure after fragmentation, and it is produced and perfected corresponding to each knowledge topic. The video teaching materials mainly come from two aspects. First, the teachers record their own lessons to form teaching and training videos (micro classes). The second method uses video materials on foreign websites to form learning videos for processing. These videos are produced in a unified and standardized manner, covering all the knowledge points of the course and correspond to the topics in the original knowledge architecture. The second type of instructional video is mainly through the collection of professional materials at home and abroad, the secondary processing of them, thus forming an instructional video for students learning to expand, mainly including: CPU manufacturing process, photolithography, etching technology, ion implantation Technology, cleanroom use precautions, preparation of silicon substrates, etc.

\subsection{Process Simulation Animation Production, Collection and Reprocessing}

Table 1. Process Simulation Video Construction Content

\begin{tabular}{l|l|l}
\hline Number & \multicolumn{1}{|c|}{ Unit } & \multicolumn{1}{|c}{ Process Simulation Animation } \\
\hline 1 & $\begin{array}{l}\text { Overview of integrated } \\
\text { circuit manufacturing } \\
\text { process }\end{array}$ & $\begin{array}{l}\text { Buried layer production, NMOS,PMOS process flow, } \\
\text { NPN,PNP process flow }\end{array}$ \\
\hline 2 & $\begin{array}{l}\text { Silicon substrate } \\
\text { preparation }\end{array}$ & $\begin{array}{l}\text { Polysilicon preparation, Pull single crystal, In-wafer } \\
\text { circular cutting, Wafer circular cutting, Polishing process }\end{array}$ \\
\hline 3 & Thin film preparation & $\begin{array}{l}\text { Thermal Oxidation Technology, Dry and wet oxygen } \\
\text { oxidation, Chemical vapor deposition, Plasma sputtering, } \\
\text { Vacuum tungsten evaporation, Epitaxial technology }\end{array}$ \\
\hline 4 & Lithography & $\begin{array}{l}\text { Lithography and electron beam, Extreme ultraviolet } \\
\text { lithography, stepper }\end{array}$ \\
\hline 5 & Etching technology & Etching process, Dry etching, Wet etching \\
\hline 7 & Doping technology & $\begin{array}{l}\text { Thermal diffusion technology, Ion Implantation, Sputtering } \\
\text { packaging technology }\end{array}$ \\
\hline
\end{tabular}

"IC manufacturing process" is a relatively practical course. But the training environment and conditions are very demanding. So the general institutions are unable to meet the training environment. Therefore, the process simulation of the training process is particularly important. It is 
to enable students to have a deeper understanding of the processes and processes. In this project development, a process simulation video was specially developed and relied on IC process simulation software. The process simulation video is shown in Table 1.

\subsection{Interaction and Self-learning, Self-testing Function Implementation}

The interactive learning and self-testing function modules are also an important part of the teaching resource library. The exchanges and interactions are mainly displayed in three ways: online question answering, exchange discussion and professional forum. Among them, professional forums is mainly managed and audited by full-time teachers. They mainly publish articles embodying academic and technical characteristics in the field of Nano-processing technology, as well as some experience posts for project development in specialized fields, providing professional learning for different learners. Online Q\&A and communication discussion are open to all learners, form a platform for everyone to conduct research and exchange, become an effective extension and extension outside the traditional teaching model, and improve learners' ability to analyze problems and solve problems.

On the basis of the production of course teaching resources, it also developed an exercise library and a test library corresponding to teaching videos and knowledge points, to provide online autonomous practice and autonomous testing functions. The online learning and on-line testing functions of the resource library website can ensure the flexibility of learning. Learners can test the mastery of the learned knowledge according to their own needs, through phased tests and result tests, etc., according to the feedback results. Adjust the learning plan and content.

\section{The Innovation of the Construction of IC Manufacturing Process Teaching Resource Library}

4.1 Professional resources closely follow the latest technology in the professional field and provide rich learning resources for different learners

The "IC Manufacturing Process" teaching resource database was jointly completed for colleges, other universities, and cooperative institutions represented by the Nano Processing Platform of the Chinese Academy of Sciences. The resources for course construction are rich and diverse, and not only has the school accumulated various teaching materials for many years. It also includes deep integration of the company's own unique corporate production factors, internships or production internships, corporate technology resources and corporate job skills and other information. Therefore, whether it is for school students or corporate employees, the "IC Manufacturing Process" teaching resource library is the best choice for learning and training.

4.2 The teaching results are obvious, and the information-based teaching conditions are significantly improved to facilitate wider use and promotion

The completed "IC Manufacturing Process" teaching resource base has provided an effective information platform for the construction of academic disciplines, the construction of microelectronics technology, and the training of professional skills for employees. On the one hand, teachers and students have successfully implemented web-assisted teaching and learning through this resource library website, which improves the professional teaching effect. On the other hand, it has used the platform to successfully carry out some professional skills training for employees of semiconductor companies in Suzhou area, and has undertaken some of the training tasks of the high-skill competition project in Suzhou Industrial Park have greatly improved social service capabilities.

\section{Conclusion}

The IC Manufacturing Process teaching resource library utilizes high-quality technical resources of schools and enterprises to be integrated with modern technology to realize the sharing of teaching resources within a certain area, promoting the reform of the teaching mode and teaching 
methods of specialty. It also effectively improves the level of microelectronics professional course construction and the quality of Nano-processing technology personnel training.

\section{References}

[1] ZHANG Zhi-yuan. The MOOCs and Chinese higher education [J]. Journal of HeBei Normal University/Educational Science Edition. 2014 (3).

[2] George L. Mehaffy, Challenge and Change, Educause Review. [EB/0L]. http://www. educause.edu/ero/article/challenge-and-change:2012-9-5/2012-10-12.

[3] Remarks of President Barack Obama-As Prepared for Delivery Address to Joint Session of congress.[EB/0L].http://www.whitehouse.gov/the_press_office/remarks-of-president-barack-obama -address -to -joint -session-of-congress: 2009-2-24/2012-10-12.

[4] William B. Bonvillian, Susan R. Singer, The online challenge to higher education [J]. Issue in Science and Technology, SUMMER 2013.

[5] Michael A. Cusumano. Are the Costs of 'Free' too high in Online education? [J]. Communications of the ACM, 2013 (4).

[6] Steve Cooper and Mehran Sahami. Education Reflections on Stanford's MOOCs 2013 [J]. Communication of the ACM. 2013 (2).

[7] Marc Claràand Elena Barberà. REFLECTION Learning online: massive open online courses (MOOCs). Connectivism, and cultural psychology [J]. Distance Education, 2013 (1). 